\title{
FASILITAS PEMANFAATAN RUMPUT LAUT DI LAUT WULA, NUSA TENGGARA TIMUR
}

\author{
Stevie $^{1)}$, Djidjin Wipranata ${ }^{2)}$ \\ 1)Program Studi S1 Arsitektur, Fakultas Teknik, Universitas Tarumanagara, stevieelhu@gmail.com \\ 2) Program Studi S1 Arsitektur, Fakultas Teknik, Universitas Tarumanagara, djidjinellya@yahoo.com
}

\begin{abstract}
Abstrak
Nusa Tenggara Timur merupakan salah satu provinsi di Indonesia yang memiliki kekayaan alam laut yang melimpah dan menjadi penghasil rumput laut terbesar kedua di Indonesia. Listrik merupakan komponen penting dalam peradaban dan modernitas, serta perkembangan pengetahuan dan informasi. Namun, seringkali Nusa Tenggara Timur mengalami kekurangan pasokan listrik dan bahan bakar untuk menjalankan aktivitas yang hingga saat ini masih bergantung dengan energi fosil yang merusak lingkungan. Maka dari itu, menyadari besarnya potensi laut yang ada, perlu dibangun suatu fasilitas pemanfaatan rumput laut yang dapat dikonversikan menjadi biofuel, yang selanjutnya dapat dikonversikan menjadi energi listrik, dan juga dapat diolah menjadi agar, karaginan, dan pupuk yang difokuskan pada Laut Desa Wula sebagai lokasi utama. Proyek ini juga dimaksudkan untuk memberikan edukasi kepada pengunjung untuk mengenal laut lebih dekat, serta mengingatkan manusia bahwa untuk bertahan hidup, kita tidak harus mengorbankan kehidupan lainnya. Proyek ini menggunakan metode desain regenerative architecture yang mengutamakan keseimbangan antara manusia, biota laut, dan laut. Proyek ini terdiri dari program industri biofuel, penghasil listrik, wisata, industri bahan baku rumput laut, tempat tinggal pekerja, dan ruang servis dengan gaya bangunan futuristik.
\end{abstract}

Kata kunci: arsitektur; biofuel; futuristik; industri; laut; listrik; rumput laut.

\begin{abstract}
East Nusa Tenggara is one of the provinces in Indonesia that has abundant marine natural wealth and is the second largest seaweed producer in Indonesia. Electricity is an important component in civilization and modernity, as well as the development of knowledge and information. However, East Nusa Tenggara often suffers from a shortage of electricity and fuel to carry out activities that are still dependent on fossil fuels that damage the environment. Therefore, realizing the enormous potential of the existing sea, it is necessary to build a facility for the use of seaweed that can be converted into biofuel, which can then be converted into electrical energy, and can also be processed into agar, carrageenan, and fertilizer focused on the Wula Village Sea as a source of energy. prime location. This project is also intended to educate visitors to get to know the sea more closely, as well as remind humans that in order to survive, we don't have to sacrifice other lives. This project uses a regenerative architecture design method that prioritizes the balance between humans, marine life, and the sea. This project consists of a program for the biofuel industry, electricity generation, tourism, seaweed raw material industry, workers' residences, and service rooms with futuristic building styles.
\end{abstract}

Keywords: architecture; biofuel; electricity; futuristic; industry; seaweed; sea. 


\section{PENDAHULUAN}

Manusia tidak dapat hidup sendiri, manusia selalu memerlukan komponen lain baik komponen hidup maupun komponen mati untuk manusia bertahan hidup, dalam hal mendapatkan makanan, mendapatkan oksigen, dan menjalankan kehidupannya. Laut merupakan sumber daya yang sering dilupakan oleh manusia. Laut yang kaya akan sumber daya, seringkali menjadi rusak karena ulah manusia, seperti pertumpahan minyak dari kapal contohnya. Pertumpahan minyak yang berasal dari kapal laut sering mematikan biota-biota laut yang ada di dalamnya, para nelayan pun sering mengeluh bahwa mereka susah untuk mendapatkan ikan akibat adanya pertumpahan minyak kapal ke laut. Selain itu juga, manusia cenderung mengotori laut dan mematikan biodiversitas yang ada di laut, padahal biodiversitas membuat kehidupan laut tetap berlangsung, dengan adanya makhluk yang saling berkaitan satu sama lain, dalam membentuk suatu simbiosis maupun suatu rantai makanan.

Indonesia merupakan Negara Kepulauan terluas di dunia, memiliki laut yang luas, dan garis pantai yang panjang. Luas perairan Indonesia adalah 5,8 juta $\mathrm{km}^{2}$ dan didalamnya terdapat $27.2 \%$ dari seluruh spesies flora dan fauna di dunia dengan presentase rumput laut sekitar $8.6 \%$ dari total biota di laut (Wawa, 2005). Potensi rumput laut perlu terus digali, mengingat tingginya keanekaragaman rumput laut di perairan Indonesia.Salah satu komponen laut yang sangat penting, namun seringkali terlupakan ialah rumput laut. Ekosistem rumput laut dunia tengah menghadapi krisis lingkungan dan perubahan iklim. Hal ini terungkap dalam laporan terbaru yang diterbitkan dalam jurnal "Global Change Biology" (Megan, 2013), peneliti dari Global Change Institute, milik University of Queensland. Setiap tahun, sebanyak 7\% hamparan rumput laut dunia hilang akibat ulah manusia. Tingkat kerusakan ini diperkirakan akan terus meningkat seiring dengan kenaikan permukaan air laut akibat pemanasan global. Padahal, rumput laut memiliki banyak sekali manfaat bukan hanya untuk manusia, ekosistem laut, bahkan dunia. Eksistensi rumput laut menciptakan suatu habitat bagi para ikan, yang berujung pada peningkatan biodiversitas. Rumput laut yang diolah juga dapat menghasilkan energi biodiesel yang ramah lingkungan dan dapat terbarukan jika dibandingkan dengan energi fosil yang semakin hari semakin menipis ketersediaannya. Rumput laut dikonversikan menjadi energi listrik yang dapat berguna bagi kemajuan peradaban manusia, selain itu rumput laut juga dapat menyerap $\mathrm{CO}_{2}$ dari atmosfer bumi dan mengubahnya menjadi $\mathrm{O} 2$ dalam proses fotosintesis, dan juga dapat dijadikan bahan makanan, kecantikan dan medis.

Nusa Tenggara Timur merupakan provinsi terbesar penghasil rumput laut kedua di Indonesia. Namun, Nusa Tenggara Timur memiliki keterbatasan ketersediaan bahan bakar dan listrik untuk menjalani aktivitas. Mengingat banyaknya manfaat yang dapat dihasilkan oleh pembudidayaan rumput laut, dapat diusulkan suatu proyek industri bioenergi rumput laut yaitu biofuel dan konversi energi menjadi listrik, serta industri bahan baku rumput laut, dan juga restorasi laut dan habitat ikan untuk mengembalikan dan mengembangkan ekosistem laut dan biodiversifikasi di laut Nusa Tenggara Timur.

\section{KAJIAN LITERATUR}

\section{Teori Ekologi}

Ekologi berasal dari bahasa Yunani 'oikos' (rumah atau tempat hidup) dan 'logos' (ilmu). Ekologi juga dapat didefinisikan sebagai pengkajian hubungan organisme-organisme atau kelompok organisme terhadap lingkungannya, atau ilmu hubungan timbal balik antara organisme hidup dengan lingkungannya (Odum, 1996). Lingkungan yang dimaksud meliputi lingkungan inorganik (abiotik) dan organik (biotik). Lingkungan biotik meliputi makhluk hidup di dalamnya yang saling terkait satu sama lain, sehingga populasi beserta fungsi dan peranannya dalam suatu lingkungan dikaji dalam ekologi (Wirakusumah, 2003). Keterkaitan dan ketergantungan komponen biotik seimbang dan stabil, karena perubahan yang satu mempengaruhi perubahan lainnya. 


\section{Teori Arsitektur Ekologis}

Arsitektur ekologis mencerminkan adanya perhatian terhadap lingkungan alam dan sumber alam yang terbatas. Secara umum, arsitektur ekologis dapat diartikan sebagai penciptaan lingkungan yang lebih sedikit mengkonsumsi dan lebih banyak menghasilkan kekayaan alam. Arsitektur tidak dapat mengelak dari tindakan perusakan lingkungan. Namun demikian, arsitektur ekologis dapat digambarkan sebagai arsitektur yang hendak merusak lingkungan sesedikit mungkin. Untuk mencapai kondisi tersebut, desain diolah dengan cara memperhatikan aspek iklim, rantai bahan, dan masa pakai material bangunan. Prinsip utama arsitektur ekologis adalah menghasilkan keselarasan antara manusia dengan lingkungan alamnya.

Unsur-unsur pokok arsitektur ekologis ialah udara (angin), air, tanah (bumi), dan api (energi) dianggap sebagai unsur awal hubungan timbal balik antara bangunan gedung dan lingkungan. Arsitektur ekologis memperhatikan siklus yang terjadi di alam dengan udara, air, tanah, dan energi sebagai unsur utama yang perlu untuk diperhatikan. Udara merupakan campuran berbagai gas (nitrogen, oksigen, hidrogen, dll.) yang tidak berwarna dan tidak berbau yang dihirup oleh manusia ketika bernapas. Udara memiliki hubungan yang erat dengan kehidupan manusia. Jika kualitas udara tercemar, maka akan mengganggu sistem pernapasan dan kualitas hidup manusia. Tanah (bumi) merupakan asal dari seluruh sumber bahan baku yang menunjang keberlangsungan hidup dari seluruh makhluk hidup. Energi merupakan elemen yang melambangkan kekuatan yang diperlukan manusia dalam melaksankan aktivitasnya. Setiap kegiatan yang dilakukan oleh manusia membutuhkan energi, seperti halnya manusia membutuhkan energi untuk memproduksi makanan dan peralatan. Air merupakan elemen yang mendukung keberlangsungan hidup manusia. Air digunakan untuk menunjang kegiatan dan aktivitas sehari-hari yang dilakukan oleh manusia, seperti minum, mandi, mencuci, serta merupakan komponen penting bagi keberlangsungan hidup organisme lain yang berada di alam seperti tumbuh-tumbuhan dan hewan.

Menurut Heinz Frick (2007: 125) ada beberapa prinsip bangunan ekologis, antara lain:

1. Menggunakan bahan baku alam tidak lebih cepat daripada alam mampu membentuk penggantinya.

2. Menciptakan sistem yang menggunakan sebanyak mungkin energi terbarukan.

3. Mengizinkan hasil sambilan (potongan, sampah, dan sebagainya) saja yang dapat digunakan atau yang merupakan bahan mentah untuk produksi bahan lain.

4. Meningkatkan penyesuaian fungsional dan keanekaragaman biologis.

\section{Peran Rumput Laut secara Ekologis}

Rumput laut Rumput laut mempunyai beberapa perbedaan bentuk dengan tumbuhan darat pada umu mnya. Pertama, mereka tidak mempunyai suatu sistem perakaran untuk mengambil nutrisi. Rumput laut mengambil makanannya melalui daun yang menyerupai tangkai yang terdapat disekelilingnya. (Isdradjad et al.,2009)

Rumput laut sebagai biota penyusun ekosistem memiliki peran secara ekologis antara lain (Tri Handayani, 2019):

\section{- $\quad$ Sebagai produsen primer}

Rumput laut berperan secara ekologis bagi ekosistem laut sebagai produsen primer dalam rantai makanan. Rumput laut memiliki pigmen fotosintetik sehingga dapat menyediakan makanan sendiri dengan bantuan sinar matahari dan nutrisi yang ada di air laut. Sebagai produsen primer, rumput laut melakukan proses fotosintesis dan menyumbang biomassa dan proporsi besar dalam produktivitas primer di ekosistem laut.

- Sebagai sumber makanan bagi biota lainnya 
Sebagai produsen primer dalam rantai makanan, rumput laut merupakan sumber pangan bagi biota laut lainnya (herbivora). Dengan adanya sistem rantai makanan, merupakan salah satu cara alami untuk menjaga keseimbangan ekosistem dengan cara mencegah terjadinya ledakan populasi di ekosistem. Ikan, bulu babi dan gastropoda umumnya menjadi pemangsa rumput laut. Rumput laut merupakan makanan utama bagi ikan laut herbivora, tempat hidup ikan herbivora di terumbu karang yang menyebabkan interaksi tidak hanya antara rumput laut dan ikan herbivora namun juga terjadi interaksi segitiga antara rumput laut, ikan herbivora dan terumbu karang.

- Sebagai tempat perlindungan

Rumput laut menjadi tempat perlindungan/habitat bagi biota laut.

- Sebagai habitat pengasuhan

Rumput laut merupakan koloni/rumpun yang dimanfaatkan oleh biota laut sebagai habitat pengasuhan. Biota laut yang umum ditemukan berada di rumpun rumput laut adalah ikan. Peran rumput laut sebagai habitat pengasuhan secara umum berkaitan dengan sumber makanan. Biota laut yang tumbuh dan berada di sekitar rumpun ini umumnya merupakan biota yang memangsa rumput laut dan menjadikan rumput laut sebagai habitat pengasuhan juga.

- Sebagai penyerap karbon

Rumput laut diketahui memiliki kemampuan menyerap karbon, sehingga dapat mengurangi pengaruh pemanasan global. Penyerapan karbon oleh rumput laut tidak hanya terjadi pada rumput laut yang tumbuh secara alami, tetapi juga yang dibudidayakan. Seperti kelp (Macrocystis \& Laminaria) memiliki laju fotosintesis dan produktivitas yang tinggi yaitu $\geq 3.000 \mathrm{~g} \mathrm{C}$ per $\mathrm{m} 2$ per tahun. Rumput laut coklat (Ochrophyta) yang memiliki laju fotosintesis paling besar adalah Sargassum, Ascophyllum dan Fucus. Namun Rhodophyta seperti Porphyra dan Palmaria memiliki laju fotositesis yang lebih tinggi daripada rumput laut coklat.

\section{METODE}

\section{Strategi Desain}

Program sebagai sebuah metode desain harus dilihat sebagai sebuah cara kerja yang membangun hubungan antara program dengan bentuk. Pertama hubungan dua arah yaitu dimana program membangun sebuah bentuk \& bentuk beradaptasi dengan program yang ditawarkan. Kedua, hubungan ketidakperdulian dimana bentuk mengakomodasi program apapun. Ketiga hubungan terputus dimana antara program dan bentuk tidak memiliki hubungan (Agustinus, 2020). Pada proyek ini menggunakan strategi desain hubungan ketidakperdulian dimana bentuk mengakomodasi program apapun.

\section{Metode Desain}

Dalam proyek ini penulis memilih metode regenerative Architecture (Littman, Jacob A., 2009:26) yang berarti:

a. Whole system design integration: Kebutuhan manusia bukan satu-satunya kebutuhan yang harus dipertanggungjawabkan dalam desain, semua sistem harus terlibat dan dipertimbangkan

b. Integration into landscape: Tidak hanya bangunan yang menjadi pusat,. Namun dapta mewujudkan elemen bangunan \& landscape, arsitektur menjadi jembatan antara artifisial dan natural.

c. Intelligent limits: Desain menciptakan keseimbangan natural pada program, ruang \& material dimanfaatkan sebagai input positif pada sistem keseluruhan.

d. Concentration: Setiap ruang diperhitungkan dengan baik dan diperlukan.

e. Intelligent construction: Sistem dikonstruksi dengan proses natural dan artifisial dapat juga berupa prefabrikasi atau rapid prototyping. 
f. Bold ecology: Menyediakan output positif untuk energi. Energi bersifat melampaui energi. Energi bersifat melampaui (energi adalah informasi, energi sebagai produksi)

g. Community: Dukungan untuk pengalaman dan praktik sosial

h. Experience of place: Menciptakan cerita, sebagai ruang yang memberikan pengalaman bagi individu dan komunitas.

i. Culture: Sejarah sosial, geologi, kualitas hidup untuk budaya diperkuat dalam desain.

\section{DISKUSI DAN HASIL}

\section{Analisis Jalur Distribusi \& Lokasi Budidaya Rumput Laut}

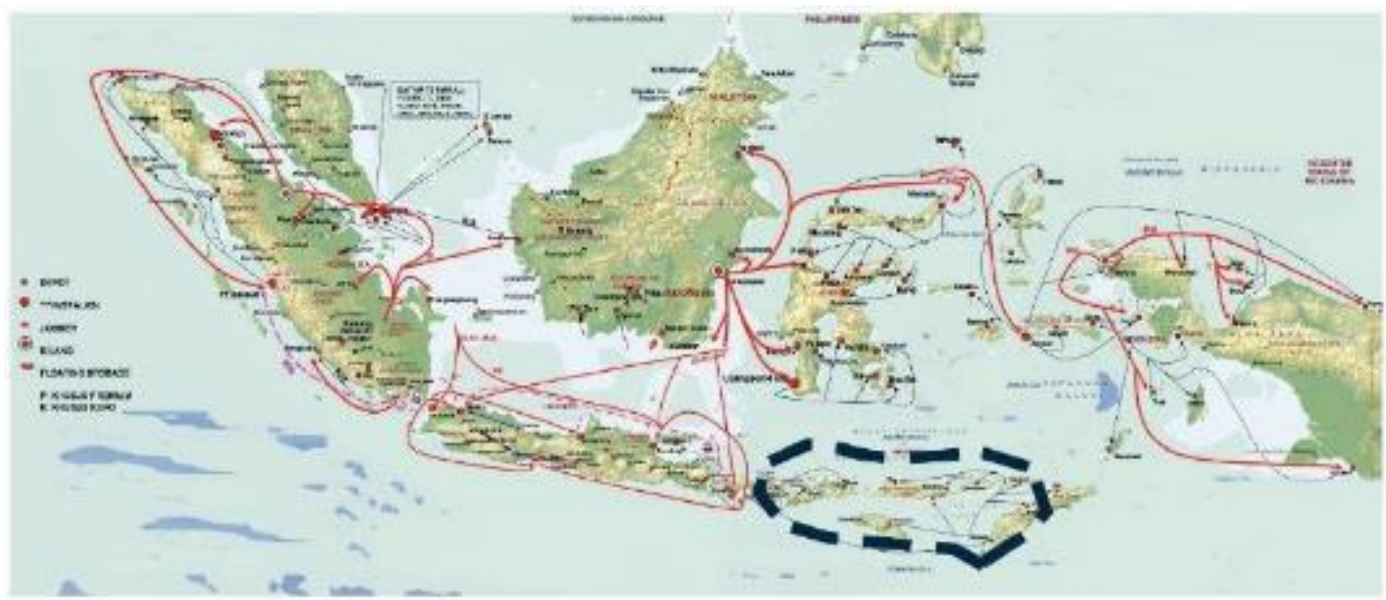

Gambar 1. Jalur Distribusi Minyak di Indonesia Sumber: https://kkp.go.id

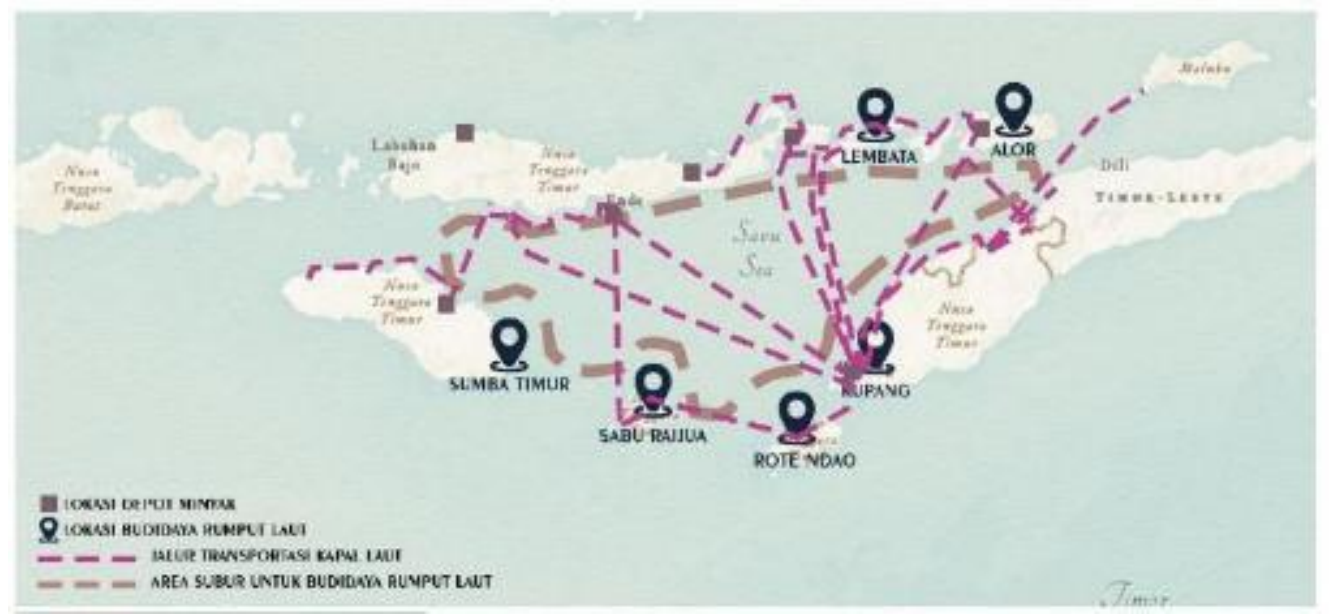

Gambar 2. Jalur Distribusi Minyak di Nusa Tenggara Timur Sumber: Dokumentasi Pribadi, 2021

Nusa Tenggara Timur merupakan daerah kedua penghasil rumput laut terbesar di Indonesia (Hasnawati et al., 2020). Dan dari data-data yang sudah diperoleh di atas, maka dapat disimpulkan bahwa Nusa Tenggara Timur memiliki akses bahan bakar fosil yang minim, yang dimana bahan bakar fosil dapat digunakan sebagai bahan bakar dan dikonversikan menjadi listrik menjadi lebih sulit dan harga di Nusa Tenggara Timur cenderung lebih tinggi. Maka dari itu, program utama dari bangunan ini ialah konversi rumput laut menjadi biofuel yang dapat digunakan sebagai bahan bakar, dan juga konversi biofuel menjadi energi listrik. 


\section{Pemilihan Tapak}

Kawasan yang terpilih sebagai lokasi pembangunan pertama adalah Desa Wula, yang terdapat di Sumba Timur yang merupakan salah satu kawasan penghasil rumput laut terbesar di Nusa Tenggara Timur. Tapak yang terpilih berada di laut bebas untuk menghindari aktivitas dan akses manusia agar budidaya dapat lebih maksimal. Selain itu, lokasi yang terpilih berjarak $700 \mathrm{~m}$ dari garis pantai Desa Wula dengan koordinat $10^{\circ} 14^{\prime} 37.3^{\prime \prime} \mathrm{S} 120^{\circ} 38^{\prime} 02.8^{\prime \prime} \mathrm{E}$ dengan kedalaman sekitar $15 \mathrm{~m}$ supaya budidaya dapat dimaksimalkan secara vertikal, jadi dengan lahan yang terbatas dapat menghasilkan panen yang maksimal.

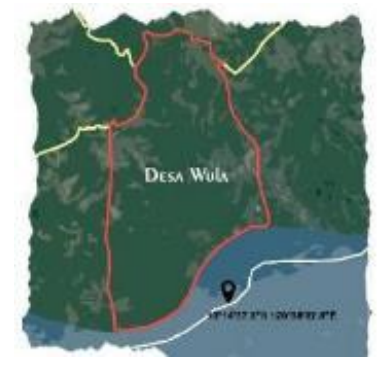

Gambar 3. Desa Wula

Sumber: Dokumentasi Pribadi, 2021

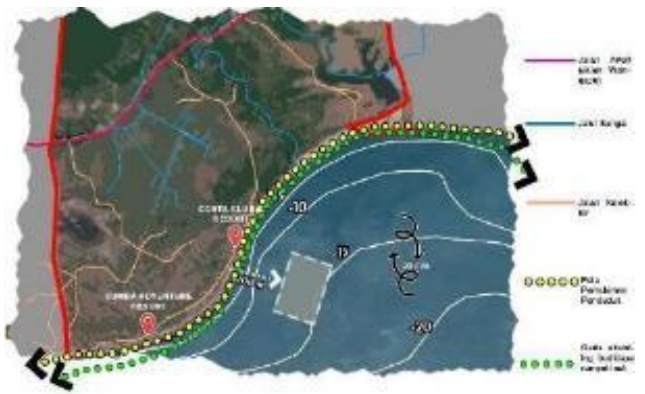

Gambar 4. Analisa Tapak di Laut Wula Sumber: Dokumentasi Pribadi, 2021

Pengaruh Tapak terhadap Bangunan
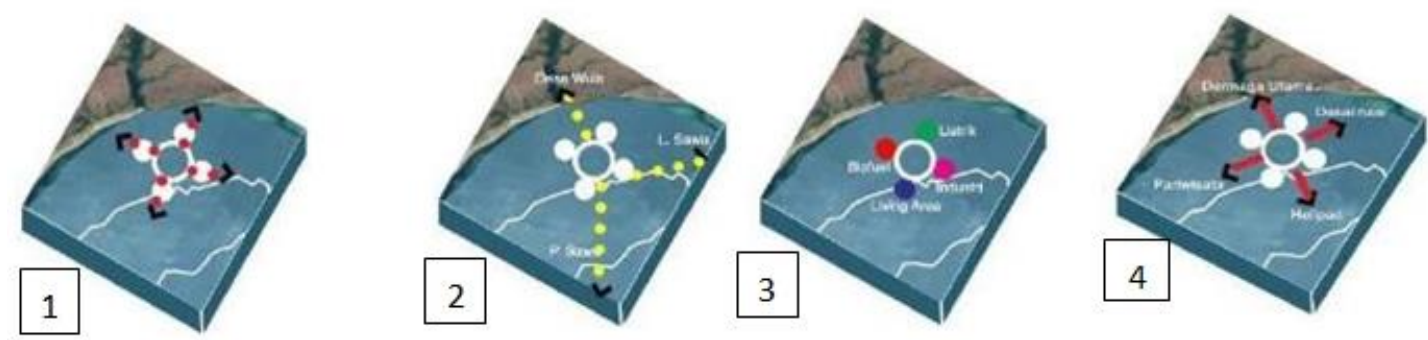

Gambar 5. Pengaruh Tapak terhadap Bangunan Sumber: Dokumentasi Pribadi, 2021

1. Orientasi (Orientasi bangunan ke segala arah untuk memberikan pengalaman hubungan dengan laut secara maksimal)

2. Lingkungan sekitar (Tapak berada di tengah laut, berjarak $700 \mathrm{~m}$ dari pantai Desa Wula)

3. Zoning (Area budidaya dan listrik diletakkan dekat pantai untuk memudahkan distribusi. Bagian industri biomassa dan living area diletakkan di belakang yang lebih privat)

4. Aksesibilitas (Dermaga utama menghadap ke arah pantai Sumba Timur)

\section{Program}

Dari data yang diatas, maka yang dapat diperhatikan adalah:

- Kawasan memiliki sedikit akses terhadap distribusi bahan bakar fosil dan juga minim pasokan listrik, padahal dua hal in merupakan hal yang sangat penting dalam kemajuan peradaban daerah.

- Kawasan merupakan kawasan yang menarik dan memiliki identitas yaitu terdapat budidaya rumput laut terbesar kedua di Indonesia.

- Kawasan merupakan kawasan pariwisata dengan kekayaan laut yang sangat indah dan luas, dan berada dalam kondisi maritim. 
- Salah satu mata pencaharian terbesar penduduk di kawasan ini merupakan petani rumput laut.

- Walaupun Nusa Tenggara Timur ini merupakan salah satu kawasan penghasil rumput laut terbesar di Indonesia, namun pemanfaatannya belum maksimal. Rumput laut yang dihasilkan dapat dimanfaatkan menjadi biofuel, yang dapat dikonversi menjadi listrik, dan dialirkan ke daratan, selain itu dapat juga diolah menjadi spirulina, karaginan, agar, jelly, dan juga makanan ringan rumput laut.

Usulan program dalam proyek :

- Industri konversi rumput laut menjadi biofuel

Rumput laut diolah menjadi biofuel yang dimana proses penanaman dilakukan oleh manusia, namun proses panen, pengeringan, dan pencacahan dilakukan oleh mesin yang disambungkan dengan conveyor agar lebih menghemat waktu dan lebih efisien. Program yang ada ialah area panen, area pengeringan, area pencacahan, area fermentasi, area ternak kerang, area istirahat pekerja, dan area penerimaan alga.

- $\quad$ Area konversi biofuel menjadi listrik

Rumput laut yang telah diolah menjadi biofuel, kemudian digunakan dalam konversi menjadi listrik untuk power-up Desa Wula dengan sistem transfomarsi melalui boiler, turbin uap, generator dan transformator. Program yang ada ialah area boiler, area turbin uap, area generator, ada transformator, area panel induk.

- $\quad$ Living Area

Diperuntukkan bagi para pekerja yang mengurus biofuel dan konversi listrik, dan juga bagi para ilmuwan yang melakukan riset pada rumput laut $\&$ biota laut. Program yang ada ialah area tempat tinggal, area berkumpul dan area tanam sayur.

- Area industri biomassa \& desalinasi air laut

Area pemberdayaan petani rumput laut dimana pada area ini alga dan rumput laut diolah menjadi bahan jadi untuk dijual dengan lebih tinggi. Desalinasi air laut merupakan area penghasil air bersih bagi bangunan. Program yang ada ialah area desalinasi air laut, area olah agar \& jelly, area olah karaginan \& spirulina, area olah kerupuk.

- Pusat massa

Area pusat sebagai penghubungantar massa pada bangunan, terdapat area publik sebagai tempat berkumpul, area seawalking dan laboratorium bawah laut. Program yang ada ialah area restoran dan cafe, area amphitheatre, area workshop dan area melihat pemandangan.

Tabel 1. Program Ruang Bangunan

\begin{tabular}{|c|c|c|c|c|c|}
\hline $\mathrm{No}$ & Nama Rvang & Luasen & 21 & Area filler air & $250 \mathrm{~m} 2$ \\
\hline 1 & Area penerimaan & $1071 \mathrm{~m} 2$ & 22 & Laboratorium & $800 \mathrm{~m} 2$ \\
\hline 2 & Dock kapal & $160 \mathrm{~m} 2$ & 23 & Galeri & $1600 \mathrm{~m} 2$ \\
\hline 3 & Area konversi biofuel & $1200 \mathrm{~m} 2$ & 24 & Workshop jelly \& agar & $320 \mathrm{~m} 2$ \\
\hline 4 & Area ikat rumput laut & $180 \mathrm{~m} 2$ & 25 & Workshop kerupuk & $320 \mathrm{mz}$ \\
\hline \multirow[t]{2}{*}{5} & \multirow{2}{*}{$\begin{array}{l}\text { Area fermentasi \& } \\
\text { penerimaan alga }\end{array}$} & \multirow[t]{2}{*}{$180 \mathrm{~m} 2$} & 26 & Workshop bioplastic & $320 \mathrm{~m} 2$ \\
\hline & & & 27 & Workshop permen & $320 \mathrm{~m} 2$ \\
\hline 6 & Area panen ternak kerang & $180 \mathrm{~m} 2$ & \multirow[t]{5}{*}{28} & Area penglihatan & $361 \mathrm{~m} 2$ \\
\hline 7 & Toilet & $30 \mathrm{~m} 2$ & & pemandangan & \\
\hline 8 & Area korwarsi listrik & $800 \mathrm{~m} 2$ & & Total area & $12.656 \mathrm{~m} 2$ \\
\hline 9 & Area istirahat pegawai biofuel & $200 \mathrm{~m} 2$ & & Sirkulasi (20\%) & $2.531 \mathrm{~m} 2$ \\
\hline 10 & Area istirahat listrik & $200 m 2$ & & Total area akhir & $15.187 \mathrm{~m} 2$ \\
\hline \multirow[t]{2}{*}{11} & \multirow{2}{*}{$\begin{array}{l}\text { Area generator, trato \& panel } \\
\text { induk }\end{array}$} & \multirow[t]{2}{*}{$60 \mathrm{~m} 2$} & & & \\
\hline & & & 1 & Lantai servis biofuel & $1500 \mathrm{~m} 2$ \\
\hline 12 & Area pengelola & $171 \mathrm{~m} 2$ & 2 & Lantai servis listrik & $740 \mathrm{mz}$ \\
\hline 13 & Area pariwisata & $814 m 2$ & 3 & Lantai servis living area & $720 \mathrm{~m} 2$ \\
\hline 14 & Area tempat tinggal & $1245 \mathrm{~m} 2$ & 4 & Lantal servis industri rumput & $720 \mathrm{mz}$ \\
\hline \multirow[t]{2}{*}{15} & \multirow{2}{*}{$\begin{array}{l}\text { Area proses karaginan \& } \\
\text { spiruline }\end{array}$} & $160 m 2$ & & laut & \\
\hline & & & \multirow[t]{2}{*}{5} & Lantai servis desalinasi & $600 \mathrm{~m} 2$ \\
\hline 16 & Aroa gudang penyimpanan & $160 \mathrm{~m} 2$ & & Total lantai servis & $4.280 \mathrm{~m} ?$ \\
\hline 17 & Area pupuk & $80 \mathrm{~m} 2$ & & & \\
\hline 18 & Area proses non & $160 \mathrm{~m} 2$ & & & \\
\hline 19 & Area publik & $814 \mathrm{~m} 2$ & & & \\
\hline 20 & Area desalinasi air laut & $500 \mathrm{~m} 2$ & & & \\
\hline
\end{tabular}

Sumber: Dokumentasi Pribadi, 2021 


\section{Transformasi Gubahan Massa}
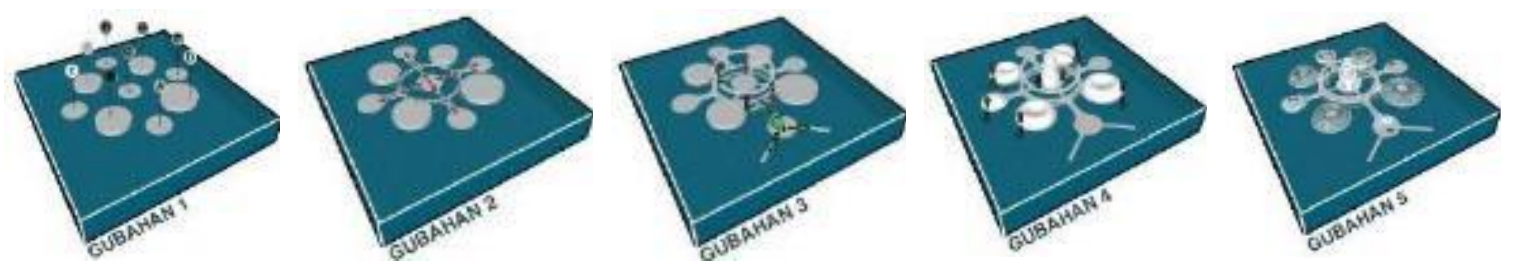

Gambar 6. Transformasi Gubahan Massa

Sumber: Dokumentasi Pribadi, 2021

1. Massa disusun berdasarkan besaran program ruang \& zoning yang telah diperhitungkan dan ditentukan (A - area penerimaan, B - Area konversi listrik, C - Area publik, D - Area konversi biofuel, E - Area desalinasi air laut, F-Area pariwisata, G-Area tempat tinggal, $\mathrm{H}$ - Area industri rumput laut, I - Area helipad). Area penerimaan, konversi listrik, dan konversi biofuel diletakkan lebih dekat ke daratan, agar mempermudah proses distribusi biofuel dan listrik ke daratan.

2. Program massa yang telah disusun, diberikan suatu penghubung dengan struktur beton apung pontoons agar pengguna bangunan dapat mengakses satu massa dengan massa yang lain.

3. Pada bagian tengah bangunan diberi atap untuk melindungi akses pejalan dari panas dan hujan, pada bagian penerimaan depan ditarik maju ke depandan ditambahkan dock sebagai shighlight bagi kapal untuk berlabuh). Struktur pada bangunan bagian tengah menggunakan struktur rangka baja yang tertancap ke dasar lautan dan bersifat permanen, sedangkan bagian massa pada sisi-sisinya menggunakan struktur apung seperti kapal yang berupa ballast tank.

4. Semua massa bangunan dibentuk atap dengan struktur dome, pada bagian yang berbentuk bulat dimaksudkan untuk photobioreactor alga agar sinar matahari dapat mengenai seluruh permukaan bangunan dan membantu proses budidaya alga yang digunakan sebagai fasad. Massa bagian tengah sebagai area publik (amphitheatre), area pengamatan pemandangan, workshop dan juga restoran.

5. Setelah massa dan struktur atap terbentuk, dipasang photobioreactor pada setiap sisi rangka ruang pada struktur atap banguna.

\section{Konsep Perancangan}

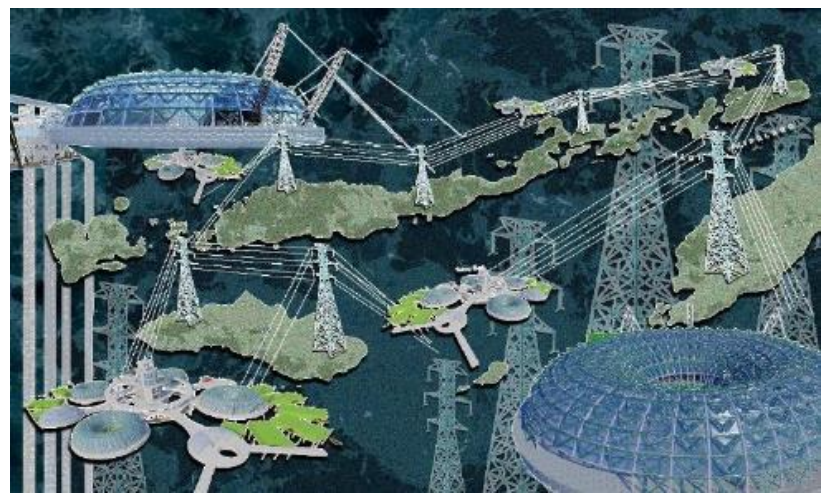

Gambar 7. Poster Penjelasan Konsep Perancangan Sumber: Dokumentasi Pribadi, 2020 
Secara keseluruhan prinsip dari bangunan ini adalah untuk kebaikan manusia, laut, dan juga ekologi yang tinggal di laut. Dalam hal ini, bangunan ini memfokuskan pada alga dan rumput laut yang sangat bermanfaat bagi ekologi. Rumput laut dan alga menjadi sumber dan fokus dalam bangunan ini, dikarenakan rumput laut dapat diolah menjadi biofuel dan listrik, spirulina, karaginan, agar, jelly, dan pupuk yang bermanfaat bagi kehidupan manusia, dan juga rumput laut dapat meningkat biodiversitas laut, dan dapat menjadi habitat bagi biota laut. Selain dibudidayakan, rumput laut juga ada yang dibiarkan tumbuh secara liar.

Selain memanfaatkan teknologi, bangunan ini juga menyediakan bagian apung bangunan sebagai platform bagi para invertebrata untuk hidup, menciptakan suatu ekosistem baru bagi makhluk hidup. Diharapkan setelah pembangunan pertama di Desa Wula, dapat dilanjutkan di titik -titik laut Nusa Tenggara Timur lainnya.

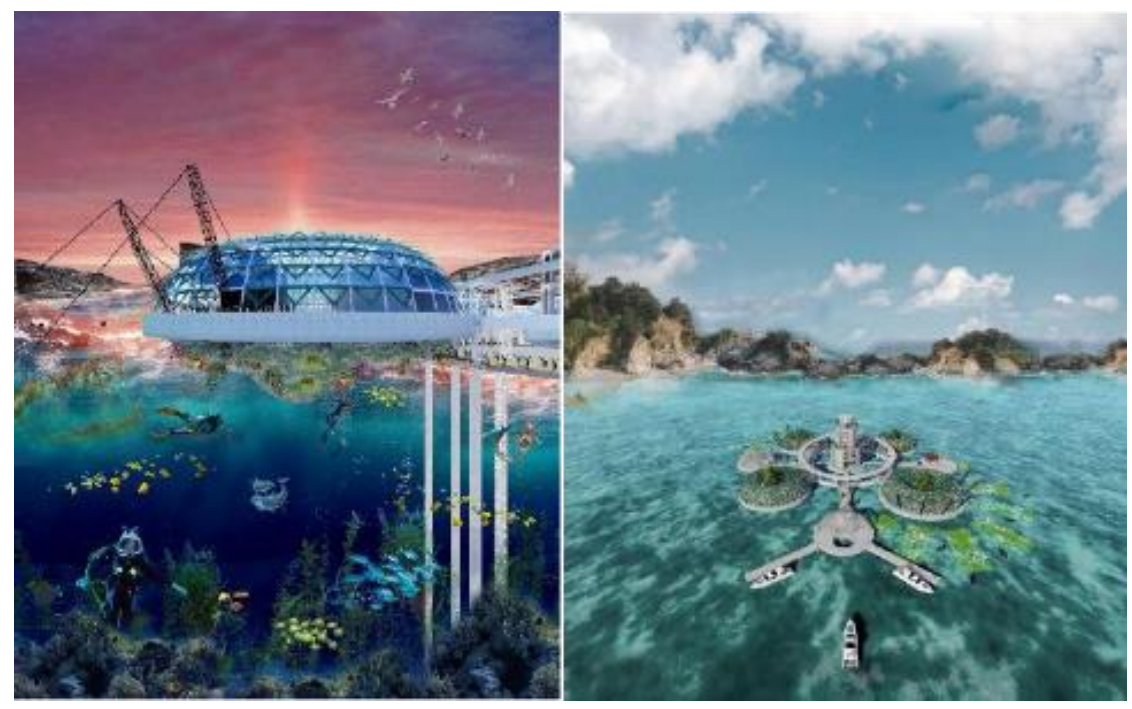

Gambar 8. Poster yang Memperlihatkan Konsep Bangunan Sumber: Dokumentasi Pribadi, 2021

Rumput laut dibudidayakan dan mengalami proses panen yang akan ditarik oleh crane pada bangunan, lalu akan menuju mesin cacah melalui mesin conveyor, lalu akan dilakukan proses fermentasi dan menjadi biofuel untuk dikonversikan menjadi listrik dan untuk memenuhi kebutuhan bahan bakar daerah Nusa Tenggara Timur.

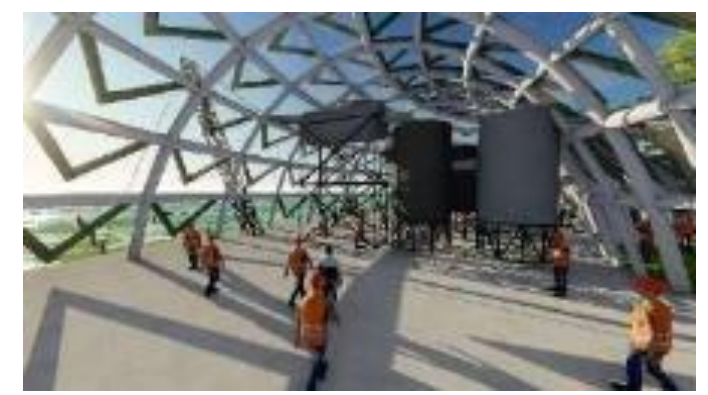

Gambar 9. Perspektif Interior Area Biofuel (kiri) \& Area Listrik (kanan)

Sumber: Dokumentasi Pribadi, 2021

Rumput laut yang telah dikonversi menjadi biofuel, akan dialirkan menuju area listrik dan akan dilakukan proses pemanasan melalui boiler, memutarkan turbin dan listrik dihasilkan dari generator, lalu ke transformer, dan dihubungkan ke powerline yang ada di daratan melalui pipa dasar, dan juga sebagian masuk ke ruang panel induk untuk dipakai untuk kebutuhan elektrikal bangunan. Selain 
rumput laut, alga juga dimanfaatkan sebagai fasad pada rumput laut, dengan budidaya melalui photobioreactor yang terletak pada fasad bangunan.

\section{Konsep Struktur}

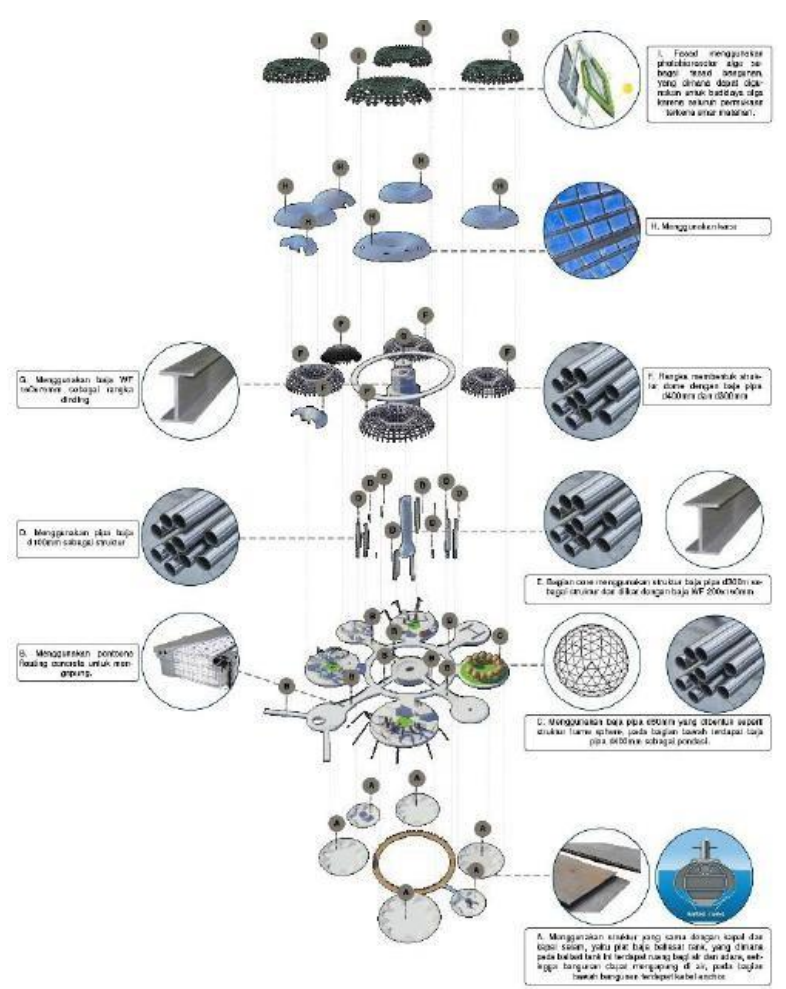

Gambar 10. Konsep Struktur dan Material Bangunan Sumber: Dokumentasi Pribadi, 2021

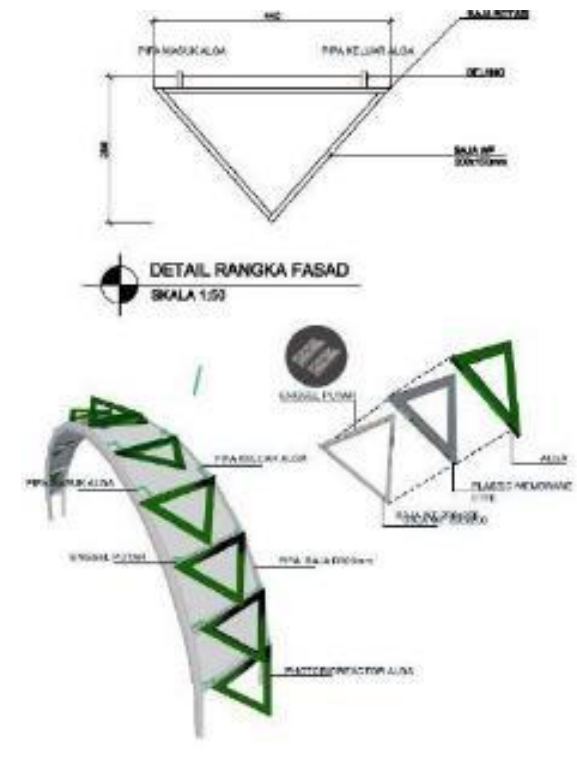

Gambar 11. Detail Fasad

Sumber: Dokumentasi Pribadi, 2021

Struktur didominasi oleh pipa baja, yang dimana struktur pada tengah bangunan merupakan struktur permanen, diikuti oleh struktur yang mengapung pada bagian sisi massa yang memiliki sistem kerja apung sama seperti kapal yang terdapat ballast tank. Fasad bangunan merupakan photobioreactor yang terisi oleh alga, dan memanfaatkan sinar matahari untuk budidayanya. 


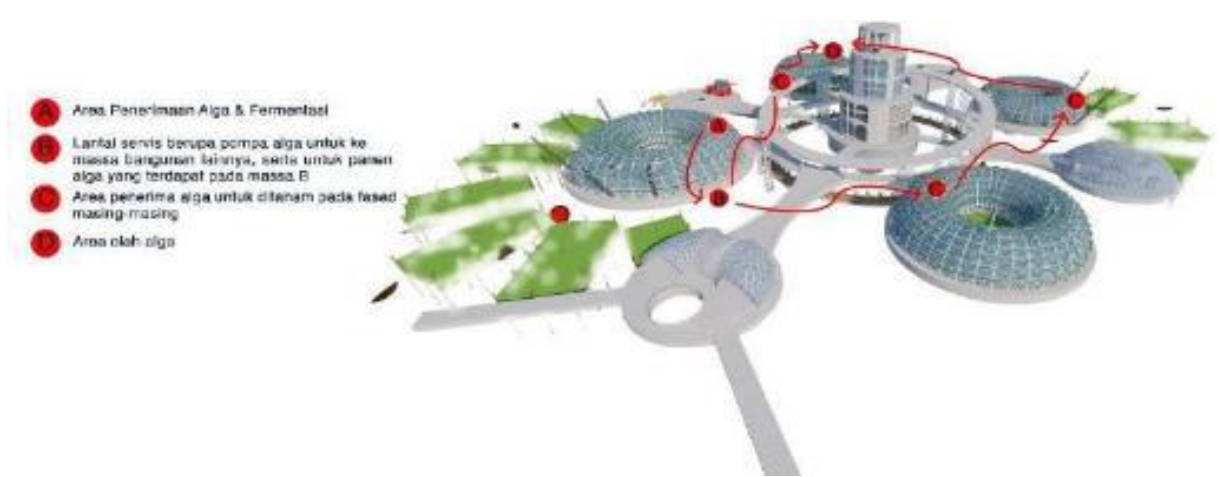

\section{Gambar 12. Sistem Fasad Photobioreactor Alga}

Sumber: Dokumentasi Pribadi, 2021

Alga dari ruang penerimaan alga akan dialirkan melalui lantai servis melalui pompa alga menuju massa bangunan lainnya, setelah itu akan diterima dan dipompa pada masing-masing fasad bangunan pada massa. Setelah panen, maka alga akan masuk ke lantai servis dan hasil panen akan dialirkan menuju area industri untuk diubah menjadi spirulina, karaginan, agar, dan pupuk.

\section{Gambar Kerja}

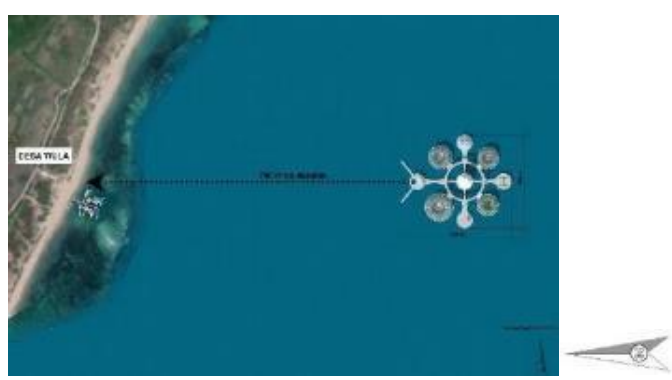

Gambar 13. Blok Plan

Sumber: Dokumentasi Pribadi, 2021

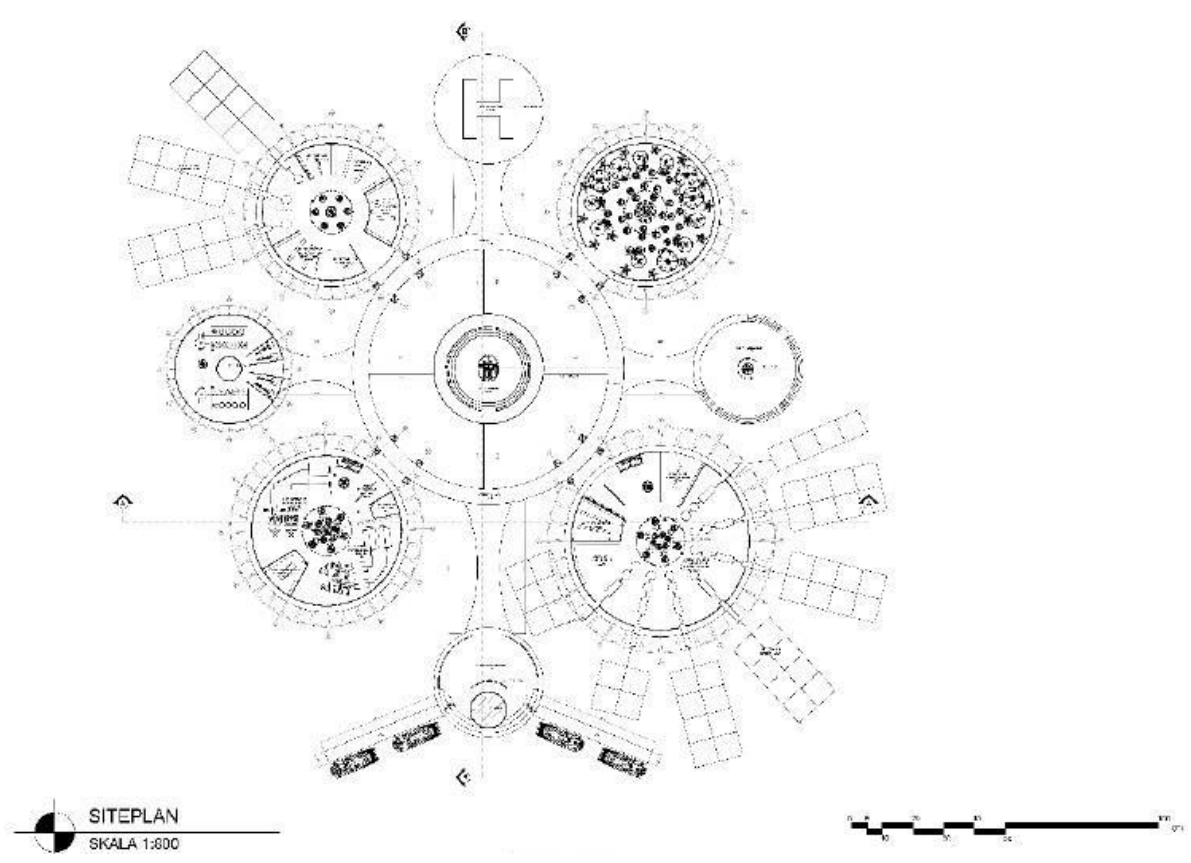

Gambar14. Site Plan

Sumber: Dokumentasi Pribadi, 2021 
Susunan massa dan ruang berbentuk bulat dan orientasinya ke segala arah untuk mendapatkan pengalaman laut secara maksimal. Penghubung antar massa menggunakan struktur beton apung pontoons. Pada bagian pusat massa merupakan area berkumpul, area workshop, dan laboratorium.
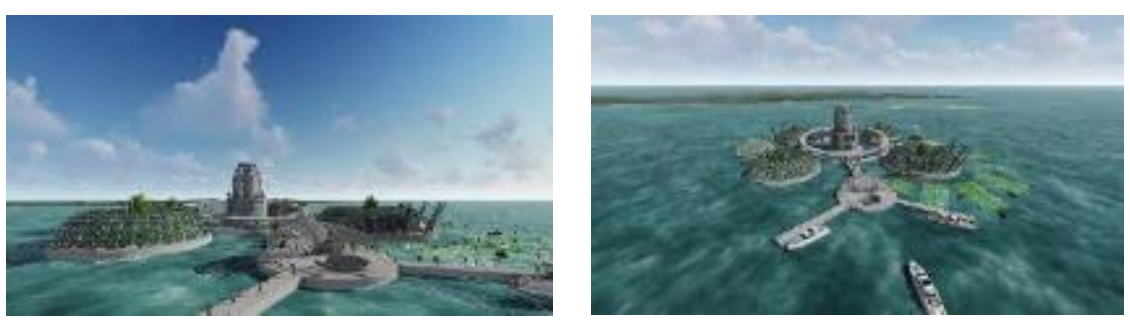

Gambar 15. Perspektif Eksterior

Sumber: Dokumentasi Pribadi, 2021
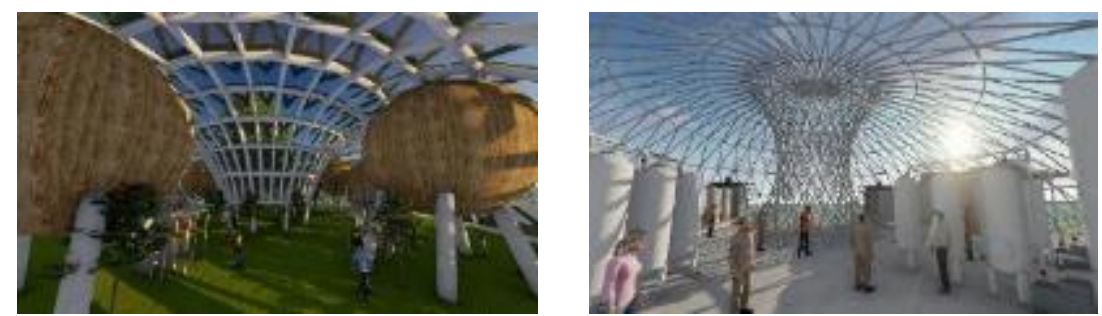

Gambar 16. Perspektif Living Area, Area Biofuel, Area Desalinasi Air Laut Sumber: Dokumentasi Pribadi, 2021

Pekerja pada proyek ini tinggal di dalam massa agar mengurangi waktu transportasi dari rumah menuju tempat kerja yang berjarak 700 meter dari pantai. Di proyek ini juga terdapat area desalinasi air laut untuk menyediakan air bersih untuk bangunan.

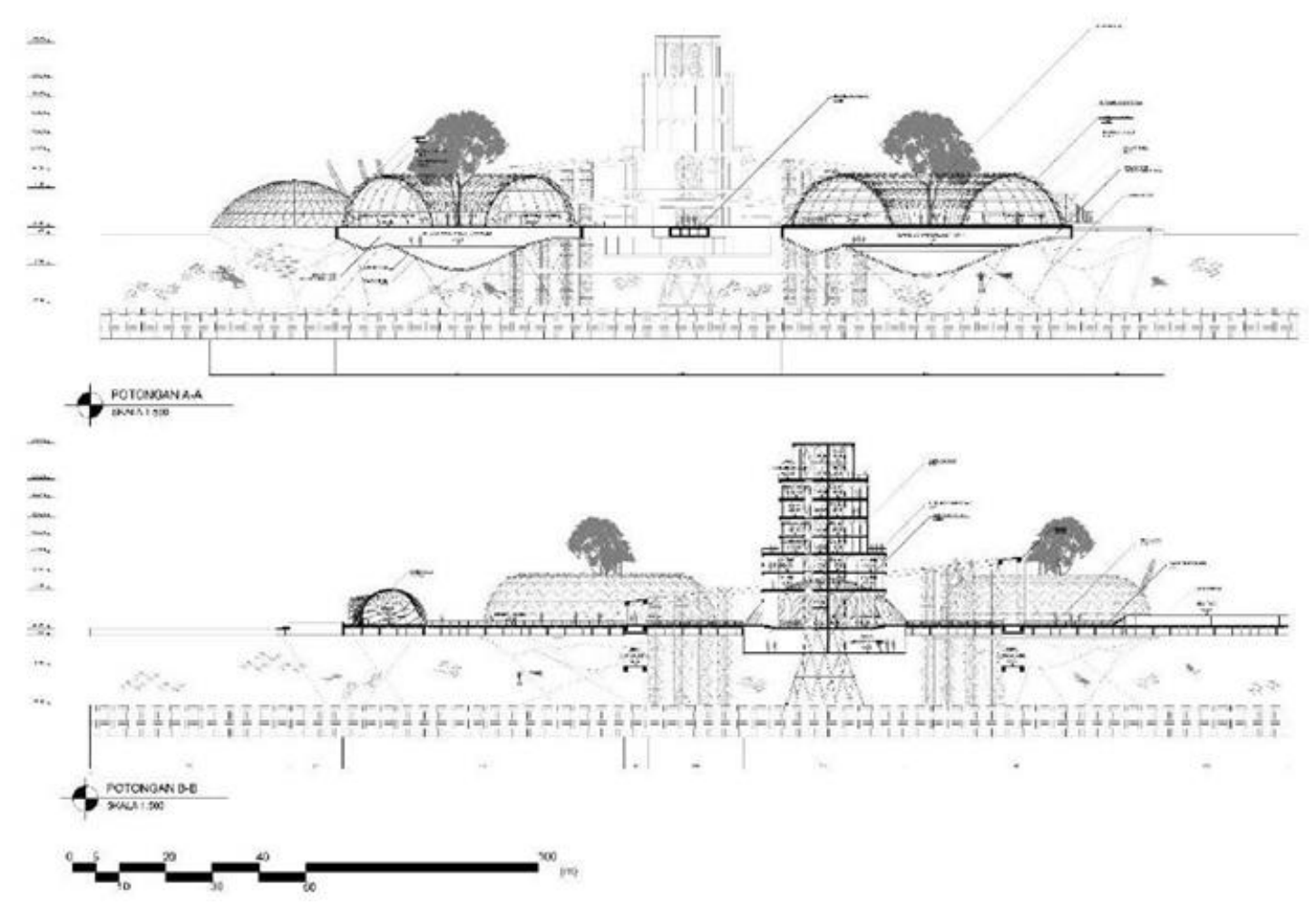

Gambar 17. Perspektif Eksterior

Sumber: Dokumentasi Pribadi, 2021 
Massa tengah memiliki struktur core yang tertancap ke dasar lautan, sedangkan massa tepi menggunakan struktur apung berupa ballast tank yang diberikan pengait berupa kabel ke dasar daratan untuk membatasi pergerakan.

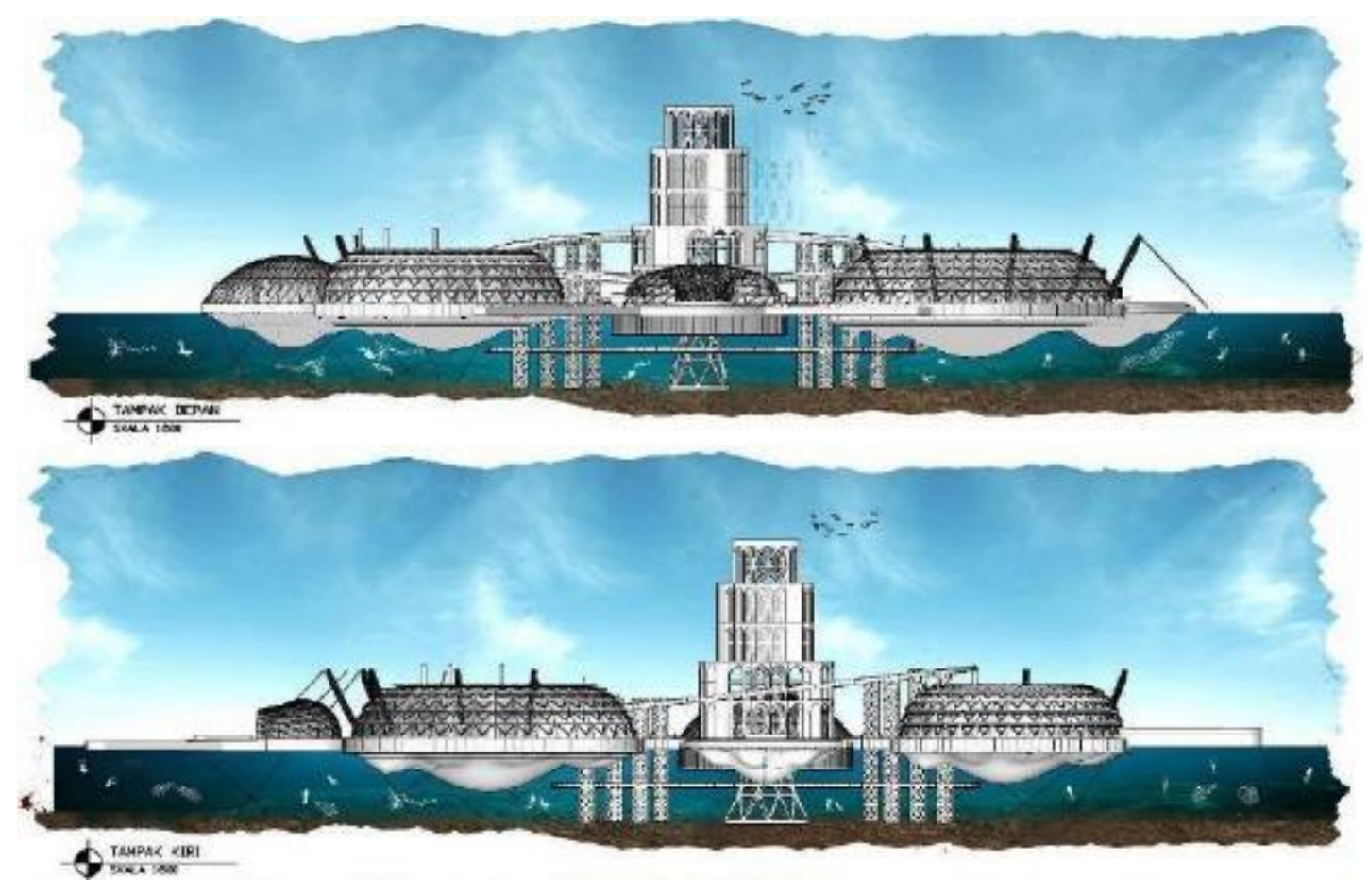

Gambar 18. Tampak Bangunan

Sumber: Dokumentasi Pribadi, 2021

Fasad bangunan terdiri dari photobioreactor alga yang memanfaatkan sinar matahari untuk bertumbuh. Sewaktu masa panen, alga akan disedot dan dimanfaatkan untuk pembuatan biofuel, agar, spirulina, dan pupuk.

\section{KESIMPULAN DAN SARAN Kesimpulan}

Proyek ini memiliki fokus untuk memberikan manfaat tidak hanya untuk manusia, namun lingkungan dan juga semua makhluk hidup yang tinggal di dalamnya, Kita sudah lama menjadi egois dengan hanya memperhatikan kehidupan kita dan mengorbankan kehidupan lain untuk bertahan hidup di dunia ini.

Proyek ini diusulkan untuk dibangun di Nusa Tenggara Timur, mengingat susahnya akses bahan bakar fosil yang sangat berpengaruh bagi kehidupan manusia, serta kekayaan alam yang melimpah di daerah tersebut. Proyek ini mengusulkan penghasilan suatu energi yang merupakan konversi rumput laut menjadi biofuel yang selanjutnya dikonversikan menjadi energi listrik, dan juga pengolahan rumput laut menjadi biomassa (agar, karaginan, spirulina, dan pupuk) yang bermanfaat bagi kehidupan manusia terutama penduduk Nusa Tenggara Timur, namun tidak melupakan bahwa eksistensi rumput laut dapat menjaga kelestarian laut bahkan menciptakan biodiversitas di laut yang dapat memperkaya laut.

Selain untuk kehidupan manusia, pada bagian bawah bangunan terdapat suatu platform yang berupa lembah dan gunung menyerupai daratan pada lautan sebagai suatu ekosistem baru bagi biota laut, 
khususnya bagi invertebrata dan habitat bagi ikan untuk bersembunyi. Dengan kekayaan alam yang melimpah, sebagian rumput laut juga dibiarkan tumbuh secara liar tanpa adanya batas, dan diharapkan dapat memberikan pengalaman bagi manusia untuk terus menghargai kehidupan makhluk hidup lainnya. Prinsip pada proyek ini ialah untuk bertahan hidup, kita tidak selalu harus mengorbankan kehidupan lainnya.

\section{Saran}

Kelanjutan dari studi yang sudah saya lakukan diharapkan dapat diteruskan dengan membangun pusat penghasil energi di lokasi lainnya terutama energi yang berasal dari rumput laut mengingat rumput laut memiliki banyak sekali manfaat bagi kehidupan kita, dan juga ekosistem laut kita

\section{REFERENSI}

Chrisnesa, Jannifer Shellyn. (2017). Pengertian Ekosistem. Diambil kembali dari http://ejournal.uajy.ac.id/11941/4/TA142293.pdfl

Frick, H. (1998). Dasar-dasar Eko-arsitektur. Yogyakarta: Penerbit Kanisius (Anggota IKAPI)

Hasnawati, Sebastian, E. (2020) . Seaweed Nation, Australia. Diambil kembali dari https://pair.australiaindonesiacentre.org/wp-content/uploads/2020/04/Seaweed-nation041720-1.pdf

Kurnia, I. dkk. (2018). Usaha dan Investasi Pengolahan Rumput Laut. Jakarta: Kementrian Kelautan dan Perikanan

Littman, J A. (2009). Regenerative Architecture: A Pathway Beyond Sustainability. Amherst: University of Massachusetts Amherst

Odum, E. P. (1996). Dasar-Dasar Ekologi. Edisi Ketiga. Yogyakarta: Gadjah Mada University Press

Saunders, Megan. (2013). Global Change Biology. University of Queensland

Setyobudiandi, I. Eddy S, Ucun luariah Bahtiar, Harmin Hari. (2009). Seri Biota Laut: Rumput Laut Indonesia \& Jenis \& Upaya Pemanfaatan. Sulawesi Tenggara : Unhalu Press

Sutanto, A. (2020). Dalam Peta Metode Desain. Jakarta.

Tri Handayani. (2019). Peranan Makroalga bagi Ekosistem laut. Diambil kembali dari https://oseana.lipi.go.id/oseana/article/view/25

Wawa, J. E. (2005, Juli 27). Pemerintah Provinsi Harus Segera Menyiapkan Lahan Pembibitan. Diambil kembali dari Berita Kompas: www.kompas.com

Wirakusumah, S. (2003). Dasar-Dasar Ekologi: Menopang Pengetahuan Ilmu-Ilmu Lingkungan. Jakarta: Penerbit Universitas Indonesia 